\title{
Maxillomandibular Deformity in a Canine with Fibrous Osteodystrophy Secondary to Chronic Kidney Disease
}

\author{
Stefanie Bressan Waller', Francisco Jucelio Correia Canuto'2, Paula Priscila Correia Costa', \\ Eduarda Alexia Nunes Louzada Dias Cavalcanti' ', Guilherme Albuquerque de Oliveira Cavalcanti' \\ Márcio Vasconcelos² \& Marlete Brum Cleff'
}

\begin{abstract}
Background: Cases of renal fibrous osteodystrophy are usually associated with nutritional causes, which of renal causes are considered uncommon in dogs. This disorder is characterized by the intense proliferation of fibrous connective tissue in bones, impairing bone stiffness. The aim of this study was to report a case of fibrous osteodystrophy secondary to chronic kidney disease in a canine with a "rubber jaw" facial deformity.

Case: A 4-year-old male unneutered mongrel dog weighing $5.2 \mathrm{~kg}$ had a history of apathy, progressive weight loss and vomiting for one month, and polyuria and polydipsia for more than three months. In addition, the owner complained about the deformed appearance in the muzzle region of the animal, which was evidenced flexibility of the same, with a displacement of the mandible and maxilla on physical examination, similar to the "rubber jaw". Blood tests revealed macrocytic anemia, elevated total plasma proteins, and lymphopenia-associated neutrophilia, as well as hyperphosphatemia (24 mg/ $\mathrm{dL})$, uremia $(283.6 \mathrm{mg} / \mathrm{dL})$ and increased creatinine $(8.6 \mathrm{mg} / \mathrm{dL})$, ALT (143.2 UI/L) and alkaline phosphatase (3222.2 $\mathrm{UI} / \mathrm{L})$, while calcium $(8.8 \mathrm{mg} / \mathrm{dL})$ and albumin $(1.9 \mathrm{~g} / \mathrm{dL})$ were decreased. A serological test for visceral leishmaniasis was also performed, which was negative. Abdominal ultrasound imaging revealed kidneys with alterations in tissue architecture, increased thickness and complete loss of cortico-medullary relationship, while the parathyroid gland was enlarged and spindle-shaped. Cranial radiography showed marked radiopacity of the bilateral maxillary bones, with destruction of the nasal, turbinate and frontal bones, as well as loosening of the teeth and destruction of the mandibular bone matrix, characterizing an aspect of "rubber jaw". Based on the history, history and evidence of azotemia, hyperphosphatemia and loss of facial bone density, the diagnosis of fibrous osteodystrophy secondary to chronic kidney disease associated with hyperparathyroidism was concluded.

Discussion: The clinical and laboratory findings reported in the present study were similar to those described in dogs with renal fibrous osteodystrophy associated with hyperparathyroidism. In the presence of azotemia, the patient was in stage 4 of chronic kidney disease which, despite investigating the infectious etiology, which was negative, remained unknown. Along with chronic kidney disease, the observation of hyperphosphatemia associated with hypokalemia contributed to the clinical investigation, whose pathophysiological mechanisms of this disorder were discussed in this study. The organic alterations observed in the patient's imaging examination coincided with the pathophysiological processes of renal fibrous osteodystrophy. The findings of renal and parathyroid alterations on ultrasound, as well as the damage to the bone matrix, maxillomandibular deformity and loss of bone support evidenced on cranial radiography, led to the conclusion of the diagnosis of renal fibrous osteodystrophy secondary to hyperparathyroidism. Despite the recommended symptomatic therapy, the patient died within 24 hours of hospitalization, and it was not possible to perform a necropsy. This report is highlighted by the occurrence of bone deformity at the maxillary and mandibular level, as a result of renal dysfunction in a young canine, alerting to the importance of complementary exams for proper diagnosis.
\end{abstract}

Keywords: hyperparathyroidism, chronic renal failure, fibrous osteodystrophy, rubber jaw, parathyroid hormone, calcium/ phosphorus ratio.

Descritores: hiperparatireoidismo, insuficiência renal crônica, osteodistrofia fibrosa, mandíbula de borracha, paratormônio, relação cálcio/fósforo. Eliseu Maciel s/n. CEP 96160-000 Capão do Leão, RS, Brazil. 


\section{INTRODUCTION}

Although fibrous osteodystrophy is commonly related to nutritional disorders from phosphorus-rich and calcium-poor diets in animals [3], the renal cause can lead to serious consequences due to the inability of the kidneys to properly excrete end products of metabolism such as urea, creatinine, phosphorus, among others $[4,7,17,19]$.

Serum increase in phosphorus leads to hypocalcemia due to the formation of a phosphate-calcium complex [16], which stimulates the parathyroid glands to produce parathyroid hormone $(\mathrm{PTH})[17,19]$. In this way, PTH acts at the bone level, performing bone digestion and thereby releasing ionized calcium into the blood [12]. In addition, chronic kidney disease further compromises the synthesis of the renal $\alpha 1$-hydroxylase enzyme [15], which is essential for the formation of the active form of vitamin $\mathrm{D}$ (calcitriol/vitamin $\mathrm{D}_{3}$ ) [17], further stimulating the $\mathrm{PTH}$ production, which contributes to the occurrence of secondary renal hyperparathyroidism [6].

Aggravatingly, this scenario may imply the most dramatic consequence, which is renal fibrous osteodystrophy [7], characterized by intense proliferation of fibrous connective tissue [13], being uncommon in dogs $[1,13,18]$. Thus, this study aimed to report a case of fibrous osteodystrophy secondary to chronic kidney disease associated with hyperparathyroidism in a canine with "rubber jaw" facial deformity.

\section{CASE}

A 4-year-old male unneutered mongrel dog weighing $5.2 \mathrm{~kg}$ was attended at a veterinary clinic in Fortaleza (Ceará, Northeast Brazil), with a history of progressive weight loss, recurrent vomiting episodes and apathy in one month ago. The owner complained about deformed appearance in the facial region and reported polyuria and polydipsia for more than three months. The animal had received regular rabies vaccination and deworming only as a puppy, was free of ectoparasites at the clinical inspection, and had no history of polyvalent vaccination.

On physical examination (Figure 1), it was observed apathy, body score $1,8 \%$ moderate dehydration, pale ocular and gingival mucous membranes, capillary filling time greater than 2 seconds, and rectal temperature of $38.4^{\circ} \mathrm{C}$. No enlargement of lymph nodes on palpation or changes in cardiac and pulmonary auscultation were observed. However, when inspec- ting and palpating the facial region, it was observed the flexibility of the muzzle region, with lateral and flaccid aspect displacement, and dental friction, when moving the mandible and the jaw, showing the appearance of a "rubber jaw". No pain on palpation in the region was noted.

Blood samples were collected for complete blood count and biochemical profile, as well as for immunochromatographic test for anti-Leishmania antibodies ( $\operatorname{IgG})$, due to the suspicion of leishmaniasis, a common infectious disease in the geographic region, which frequently causes chronic kidney disease in animals. Abdominal ultrasound imaging and cranial radiography were also performed.

Blood tests (Table 1) showed macrocytic anemia (red blood cells: $4.67 \times 10^{6} / \mu \mathrm{L}, \mathrm{VCM}$ : 82.6 $\mathrm{fL})$, with high total plasma proteins $(8.6 \mathrm{~g} / \mathrm{dL})$, and a neutrophilic picture $(15,159 \mu \mathrm{L})$ associated with lymphopenia $(815 \mu \mathrm{L})$, while the other erythrogram and leukogram parameters were within normal limits. At the biochemical examination, all parameters analyzed were altered, which the phosphorus $(24 \mathrm{mg} / \mathrm{dL})$, creatinine $(8.6 \mathrm{mg} / \mathrm{dL})$ and urea $(283.6 \mathrm{mg} / \mathrm{dL})$ values were increased by at least four times the maximum reference value for the species. High values for ALT (143.2 UI/L) and alkaline phosphatase (3222.2 UI/L) enzymes were also found, while calcium $(8.8 \mathrm{mg} / \mathrm{dL})$ and albumin $(1.9 \mathrm{~g} / \mathrm{dL})$ were below normal reference limit (Table 1). Regarding the immunochromatographic test for visceral leishmaniasis, this was negative.

At the ultrasound examination, normal aspects, sizes and shapes were found in the liver, spleen, stomach, urinary bladder and prostate. Similar findings occurred in the pancreas and adrenal glands, which were not visualized, indicating their normal topographies. There were no signs of lymphadenomegaly or presence of free abdominal fluid. However, changes in the gallbladder, kidneys and parathyroid gland were observed. In the gallbladder, despite presenting thin walls with standard echogenicity, its content was anecogenic. In the kidneys (Figure 2), despite being in normal location, size and contour, preservation of tissue architecture were impaired, cortical thickness and echogenicity were increased, showing complete loss of cortico-medullary relationship, and vascular resistance. renal artery enlargement (RD-IR=0.70 / RE-IR=0.76). No cysts, masses, stones or kidney hydronephrosis were detected. Regarding the parathyroid gland (Figure 
2), the shape was spindle-shaped and enlarged (0.91 $\mathrm{cm}$ on the left side, and $0.85 \mathrm{~cm}$ on the right side, on a larger axis), heterogeneous in the left lobe, and with increased echogenicity.

Radiographic examination of the cranial region (Figure 3) showed marked radiopacity of the bilateral maxillary bones, with the presence of nasal and turbinate bones destruction to the frontal bones, and loss of the hard blade in the periodontal region, characterizing loss of support and loosening of the teeth ("flying teeth"). The bone matrix of the right and left jaws was destroyed, including the mandibular epichonds. The animal presented right lateral displacement of the left mandible axis, with the absence of the mandibular bones, presenting appearance of "flying teeth", characteristic of "rubber jaw". The venereal bone of the hard palate was not evident and could be a bone destructive process, and the tympanic bullae were radiolucent, with thin and regular edges, without signs of liquid collections.

Based on history, anamnesis, physical examination and laboratory findings of azotemia and hyperphosphatemia, as well as the loss of facial bone density, the animal was diagnosed with fibrous osteodystrophy secondary to chronic kidney disease associated with hyperparathyroidism.

During consultation and hospitalization, the animal underwent intravenous fluid therapy with Ringer lactate supplemented with vitamins, calcium and other minerals, ranitidine $(2 \mathrm{mg} / \mathrm{kg}$, twice daily, subcutaneously) and metoclopramide $(0.4 \mathrm{mg} / \mathrm{kg}$, twice daily, subcutaneously) due to gastrointestinal disturbances. However, no improvement was observed over a $24 \mathrm{~h}$ period. Thus, given the patient's clinical condition and unfavorable prognosis, euthanasia was performed using propofol, followed by potassium chloride, both intravenously, at the request of the owner, who did not authorize the necropsy.

\section{DISCUSSION}

Early clinical signs of polyuria and polydipsia associated with gastrointestinal signs suggest a picture of chronic kidney disease [14,17], common signs in dogs with fibrous osteoarthritis, regardless of whether young [7] or elderly [1,9,13]. Although the development of chronic kidney disease is related to advanced age $[2,17]$, the patient in question was young, and the possibility of an infectious cause due to visceral leishmaniasis was ruled out, because the patient was negative in the rapid serological test. Although this nephropathy may be related to hereditary factors [5], the exact cause in the patient remained unknown.

Loss of renal function leads to several consequences in the body, and failure of renal erythropoietin secretion is a contributing factor to the occurrence of non-regenerative anemia $[6,20]$, as this substance is needed to stimulate red blood cell production in the bone marrow. In addition, the chronic stress of the patient due to the pathological condition led to the intense release of cortisol by the adrenal gland, reflecting the stress leukogram finding, that is, lymphopenia-associated neutrophilia, without left shift [20], as shown in the patient's leukogram.

Azotemia (elevated serum urea and creatinine), hyperphosphatemia, hypoalbuminemia, and hypocalcemia were all reflected of the severe impairment of renal function [17], as the low glomerular filtration rate by the few functional nephrons disrupted the kidneys to filter and eliminate urea, creatinine and phosphorus, and reabsorbing albumin and calcium. When creatinine levels are above $5 \mathrm{mg} / \mathrm{dL}$ in dogs, as observed in the patient $(8.6 \mathrm{mg} / \mathrm{mL})$, the chronic kidney disease is in stage 4 [14]. This stage presents a high risk of systemic signs and uremic seizures [14], due to the serum accumulation of nitrogenous residues such as urea and creatinine, which stimulate the chemoreceptor trigger zone and irritate the intestinal mucosa [10], explaining the signs of vomiting and progressive weight loss.

Knowing that phosphorus has a high affinity to complex with ionized calcium in the blood, forming a phosphate-calcium complex [16], the patient's hyperphosphatemia led to hypocalcemia, according to the biochemical profile. Because of the reduction in free calcium, the parathyroid glands are stimulated to produce high levels of PTH, altering bone remodeling [19], which was evidenced by ultrasound examination, which showed enlarged parathyroid glands in the patient. Thus, this bone change occurs because hyperphosphatemia stimulates the production of fibroblast growth factor-23 (FGF-23) [8], a hormone produced by bones that inhibits the synthesis of calcitriol (active form of vitamin D) [11].

This is because hyperphosphatemia inhibits the activity of the renal $\alpha 1$-hydroxylase enzyme present in the proximal renal tubule epithelium [15], which is necessary for the synthesis of calcitriol. Once at low levels, 


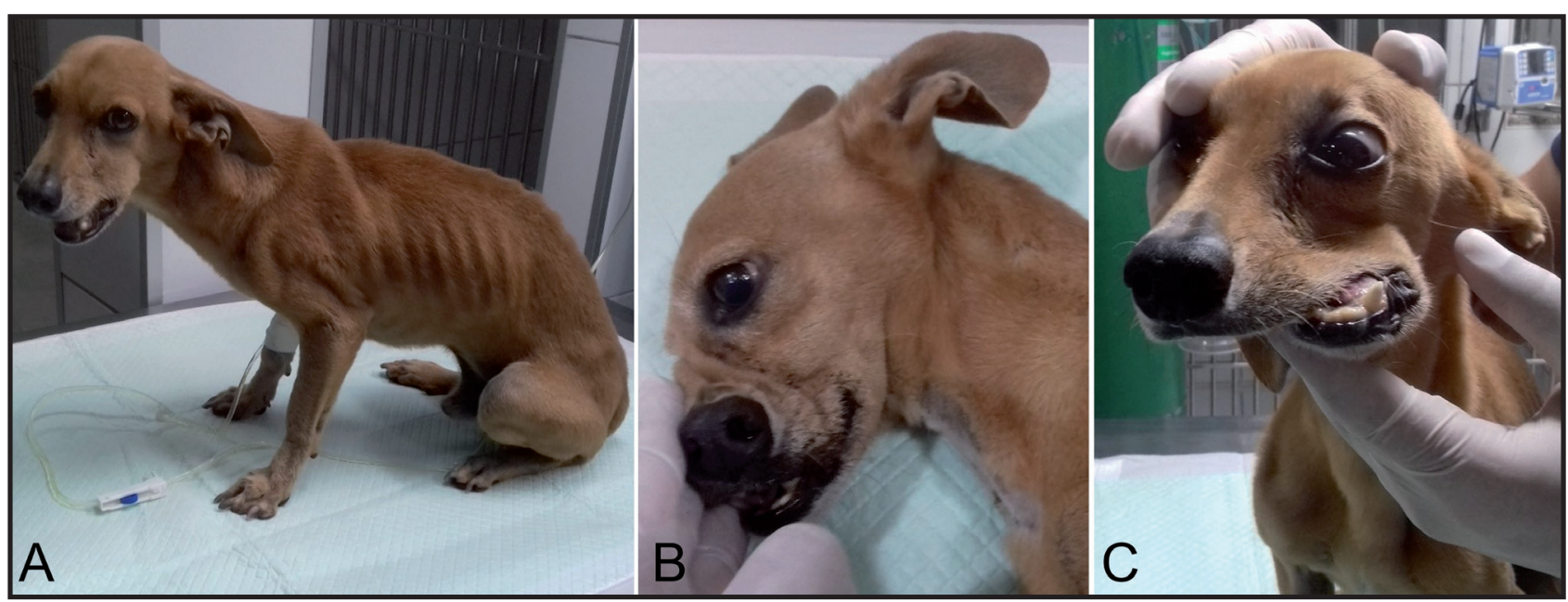

Figure 1. Physical examination of a four-year-old male mongrel dog with fibrous osteodystrophy secondary to chronic kidney disease, with body score 1 (A) and muzzle flexibility, with lateral dislocation and dental friction between the maxillary bone (B) and the mandible (C), characteristic of "rubber jaw".

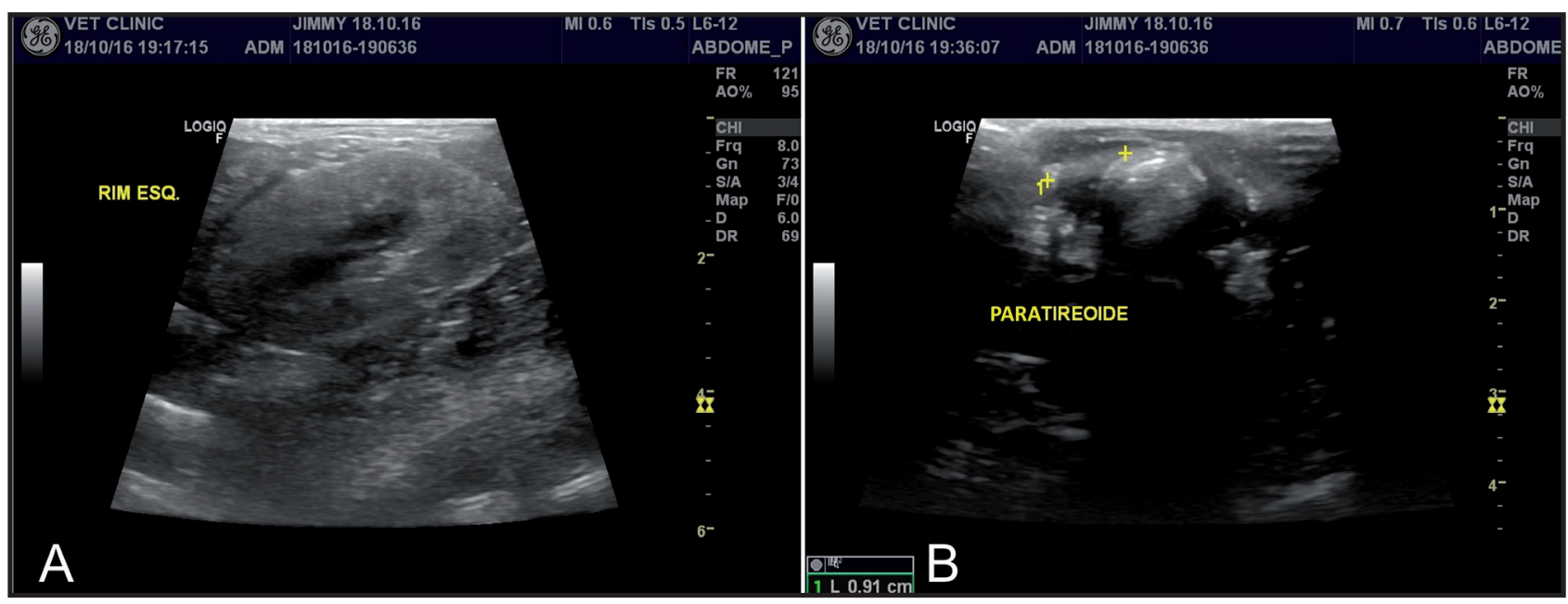

Figure 2. Abdominal ultrasound examination in a dog with fibrous osteodystrophy secondary to chronic kidney disease, showing loss of cortical-medullary definition in the left kidney (A) and increased size and echogenicity of the parathyroid gland (B).

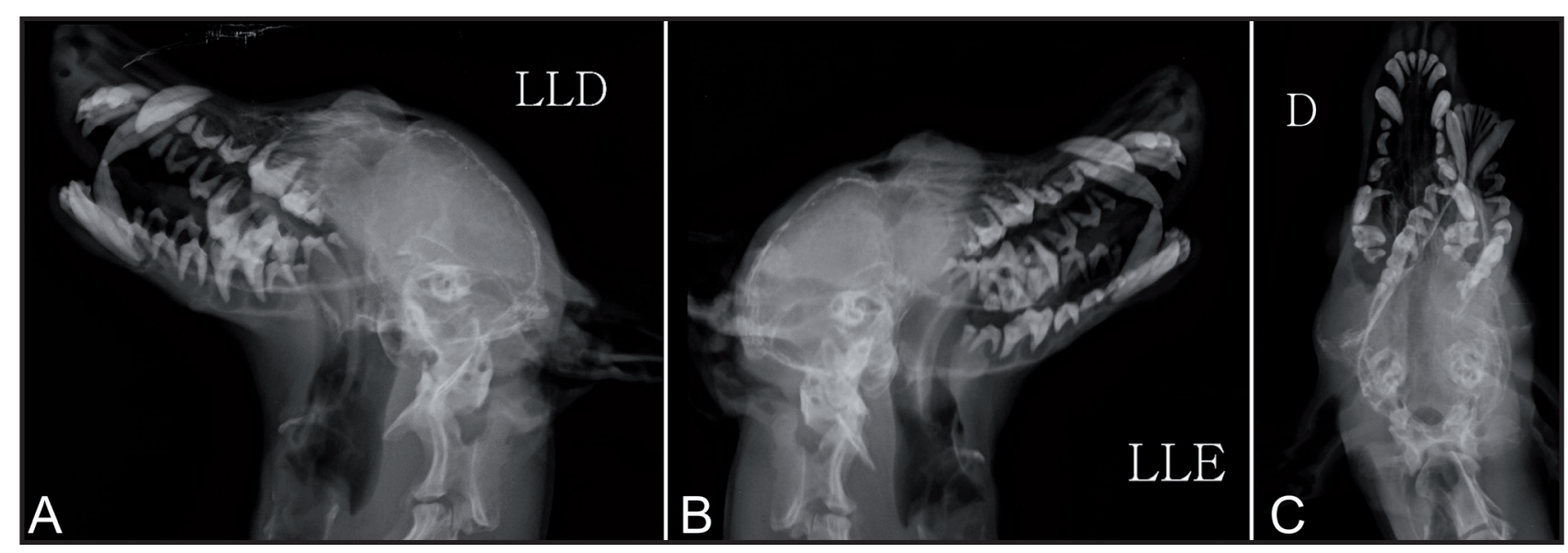

Figure 3. Cranial radiographic examination in a dog with fibrous osteodystrophy secondary to chronic kidney disease, showing the destruction of the bone matrix of the right mandible (A) in a right lateral-lateral projection (LLD), and of the left mandible (B) in a left lateral-lateral projection (LLE). The right lateral displacement of the left mandible axis and the absence of mandibular bones were observed, with the presence of "flying teeth" (C) in ventral-dorsal projection (D). 
Table 1. Hematological and biochemical profile of a canine with fibrous osteodystrophy secondary to chronic kidney disease.

\begin{tabular}{|c|c|c|c|c|}
\hline Clinical parameter & \multicolumn{2}{|c|}{ Values patient } & \multicolumn{2}{|c|}{ Reference values - canine } \\
\hline \multicolumn{5}{|l|}{ Erythrogram } \\
\hline Red blood cells & \multicolumn{2}{|c|}{$4.67 \times 10^{6} / \mu \mathrm{L}$} & \multicolumn{2}{|c|}{$5.5-8.5 \times 10^{6} / \mu \mathrm{L}$} \\
\hline Hemoglobin & \multicolumn{2}{|c|}{$12.7 \mathrm{~g} / \mathrm{L}$} & \multicolumn{2}{|c|}{$12-18 \mathrm{~g} / \mathrm{L}$} \\
\hline Hematocrit & \multicolumn{2}{|c|}{$38 \%$} & \multicolumn{2}{|c|}{$24-45 \%$} \\
\hline $\mathrm{MCV}$ & \multicolumn{2}{|c|}{$82.6 \mathrm{fL}$} & \multicolumn{2}{|c|}{$60-77 \mathrm{fL}$} \\
\hline $\mathrm{MCHC}$ & \multicolumn{2}{|c|}{$33.4 \%$} & \multicolumn{2}{|c|}{$32-36 \%$} \\
\hline RDW & \multicolumn{2}{|c|}{$13.6 \%$} & \multicolumn{2}{|c|}{$12-15 \%$} \\
\hline Platelets & \multicolumn{2}{|c|}{$396 \times 10^{3} / \mu \mathrm{L}$} & \multicolumn{2}{|c|}{$200-500 \times 10^{3} / \mu \mathrm{L}$} \\
\hline Total plasma proteins & \multicolumn{2}{|c|}{$8.6 \mathrm{~g} / \mathrm{dL}$} & \multicolumn{2}{|c|}{$5.8-7.9 \mathrm{~g} / \mathrm{dL}$} \\
\hline \multicolumn{5}{|l|}{ Leukogram } \\
\hline \multirow[t]{2}{*}{ Total leukocytes count } & \multicolumn{2}{|c|}{$16.300 / \mu \mathrm{L}$} & \multicolumn{2}{|c|}{$6.000-17.000 / \mu \mathrm{L}$} \\
\hline & Relative $(\%)$ & Absolut $(\mu \mathrm{L})$ & Relative (\%) & Absolut $(\mu \mathrm{L})$ \\
\hline Neutrophils & 93 & 15.159 & $60-77$ & $3.000-11.500$ \\
\hline Band neutrophils & 0 & 0 & $0-3$ & $0-500$ \\
\hline Promyelocyte & 0 & 0 & - & - \\
\hline Myelocyte & 0 & 0 & - & - \\
\hline Metamyelocyte & 0 & 0 & - & - \\
\hline Basophils & 0 & 0 & $0-1$ & $0-1$ \\
\hline Eosinophils & 0 & 0 & $2-10$ & $100-1.250$ \\
\hline Lymphocytes & 5 & 815 & $13-30$ & $1.000-4.800$ \\
\hline Monocytes & 2 & 326 & $3-10$ & $150-1.350$ \\
\hline \multicolumn{5}{|l|}{ Biochemical } \\
\hline Calcium & \multicolumn{2}{|c|}{$8.8 \mathrm{mg} / \mathrm{dL}$} & \multicolumn{2}{|c|}{$9.0-11.3 \mathrm{mg} / \mathrm{dL}$} \\
\hline Phosphorus & \multicolumn{2}{|c|}{$24 \mathrm{mg} / \mathrm{dL}$} & \multicolumn{2}{|c|}{$2.6-6.2 \mathrm{mg} / \mathrm{dL}$} \\
\hline Creatinine & \multicolumn{2}{|c|}{$8.6 \mathrm{mg} / \mathrm{dL}$} & \multicolumn{2}{|c|}{$0.8-1.8 \mathrm{mg} / \mathrm{dL}$} \\
\hline Urea & \multicolumn{2}{|c|}{$283.6 \mathrm{mg} / \mathrm{dL}$} & \multicolumn{2}{|c|}{$21.4-59.92 \mathrm{mg} / \mathrm{dL}$} \\
\hline Albumin & & & 2.6 & $\mathrm{~g} / \mathrm{dL}$ \\
\hline ALT/TGP & 143 & $\mathrm{I} / \mathrm{L}$ & 21 & $\mathrm{~J} / \mathrm{L}$ \\
\hline Alkaline phosphatase & 322 & $\mathrm{I} / \mathrm{L}$ & $20-$ & $\mathrm{UI} / \mathrm{L}$ \\
\hline
\end{tabular}

the function of absorbing calcium from the intestinal tract through calcitriol is reduced, leading to hypocalcemia, which in turn further stimulates PTH production [11], leading to secondary renal hyperparathyroidism.

Once at high serum levels, PTH strongly stimulates osteoclasts to perform bone digestion, releasing ionized calcium into the blood [12]. However, because calcium is responsible for the stiffness of the bone matrix, its excess removal weakens the bone, which becomes flexible and subject to fractures $[9,21]$. This risk depends on the degree of renal dysfunction, as the accumulation of uremic toxins induces PTH skeletal resistance [21], impairing bone strength and quality.

Although increased jaw size is a common sign $[1,9,11,18]$, this finding was not evidenced in the patient, indicating that is not Always observed in renal fibrous osteodystrophy [13]. In turn, bone flexibility in the maxillo-mandibular region is a common finding in dogs up to 4 years old, probably due to the still incomplete skeletal maturation [7], corroborating the age of 
the reported case. However, this finding may also occur in older dogs [9]. This feature is mainly evidenced in the mandible and maxilla $[1,9,13,18]$, as observed in the physical examination and radiographic images of the patient, and whose loss of bone support coincides with the literature $[1,13,18]$.

The prognosis of fibrous osteodystrophy secondary to chronic kidney disease due to secondary hyperparathyroidism is unfavorable $[1,9,13]$, leading to death or euthanasia request, as occurred in the animal. Although necropsy could not be performed on the patient, cases of this disorder in dogs often reveal gross anatomical appearance of the kidneys, with reduced size and nodular surface, and reduced cortex [18], similar to ultrasound findings, which the architecture tissue of the patient's kidneys were altered and with loss of cortico-medullary definition. The liver also usually shows histological compromise, with damage to the liver parenchyma [18], which may justify the high values of ALT and alkaline phosphatase in the biochemical profile, showing liver damage, with consequent release of these enzymes in the bloodstream. In relation to bone tissue, necropsy findings usually reveal a soft and elastic aspect, easily cut, and intense reduction of bone tissue, with replacement by connective tissue [18]. Given the maxillomandibular deformity, these findings reveal the alteration of bone matrix stiffness by connective tissue, justifying the flexibility of bone tissue in the patient's facial region.

This study reported a case of fibrous osteodystrophy due to the chronic kidney disease in a dog presenting mandibular bone destruction, highlighting to the importance of complementary exams for proper diagnosis.

Declaration of interest. The authors report no conflicts. All authors approved the manuscript and its submission to the journal.

\section{REFERENCES}

1 Alves M.A.M.K., Crivellenti L.Z. \& Carvalho M.B. 2014. Osteodistrofia fibrosa de origem renal em dois cães idosos: relato de caso. Revista Portuguesa de Ciências Veterinárias. 109(589-590): 51-56.

2 Bartges J.W. 2012. Chronic kidney disease in dogs and cats. Veterinary Clinics of North America - Small Animal Practice. 42(4): 669-692.

3 Becker N., Kienzle E. \& Dobenecker B. 2012. Calcium deficiency: a problem in growing and adult dogs: two case reports. Tierarztl Prax Ausg K Kleintiere Heimtiere. 40(2): 135-139.

4 Brachthäuser L., Pingen C.H., Hecht W. \& Reinacher M. 2013. Rubber jaw in a Weimaraner dog due to juvenile nephropathy. A case without evidence for genetic involvement. Tierarztl Prax Ausg K Kleintiere Heimtiere. 41(3): 198-202.

5 Clark S.D., Song W., Cianciolo R., Lees G., Nabity M. \& Liu S. 2019. Abnormal Expression of miR-21 in Kidney Tissue of Dogs With X-Linked Hereditary Nephropathy: A Canine Model of Chronic Kidney Disease. Veterinary Pathology. 56(1): 93-105.

6 Coelho F.S., Souza R.F.P., Haick A.P., Queiroz R.M., Silva A.K. \& Bonello F.L. 2013. Hiperparatireoidismo Renal Secundário em Cadela - Relato De Caso. Ciências Agrárias e da Saúde. 9: 82-88.

7 Davis E.M. 2015. Oral Manifestations of Chronic Kidney Disease and Renal Secondary Hyperparathyroidism: A Comparative Review. Journal of Veterinary Dentistry. 32(2): 87-98.

8 Dittmer K.E., Perera K.C.\& Elder P.A. 2017. Serum fibroblast growth factor 23 concentrations in dogs with chronic kidney disease. Research in Veterinary Science. 114: 348-350.

9 Ditzel B.M., Portella J.E. \& Caron V.F. 2017. Hiperparatireoidismo secundário renal em cão: relato de caso. Revista Eletrônica Biociências, Biotecnologia e Saúde. 18: 76-78.

10 Elliot J. 2019. Treatment of Vomiting, Nausea and Inappetence in Cats with Chronic Kidney Disease. International Renal Interest Society. [Fonte: http://www.iris-kidney.com/education/treatment_of_vomiting.html]. [Accessed online in July 2019].

11 Foster J.D. 2016. Update on Mineral and Bone Disorders in Chronic Kidney Disease. Veterinary Clinics of North America: Small Animal Practice. 46(6): 1131-1149.

12 Fraser W.D. 2009. Hyperparathyroidism. Lancet. 374(9684): 145-58.

13 Freitas R.A., Porto A.F., Santos Filho M. \& Paiva J.P. 2017. Osteodistrofia fibrosa em canino idoso secundário à doença renal crônica: relato de caso. Brazilian Journal of Veterinary Medicine. 39(3): 215-220.

14 International Renal Interest Society. 2017. IRIS staging of CKD. [Fonte: http://www.iris-kidney.com/guidelines/ staging.html]. [Accessed online in October 2018]. 
15 Meuten D. 2015. Avaliação e Interpretação Laboratorial do Sistema Urinário. In: Thrall M.A., Weiser G., Allison R.W. \& Campbell T.W. (Eds). Hematologia e Bioquímica Clínica Veterinária. 2.ed. Rio de Janeiro: Guanabara Koogan, pp.689-1206.

16 Moe S.M. 2008. Disorders Involving Calcium, Phosphorus, and Magnesium. Primary Care. 35(2): 215-237.

17 Polzin D.J. 2011. Chronic Kidney Disease. In: Bartges J. \& Polzin D.J. (Eds). Nephrology and Urology of Small Animals. Hoboke: Wiley-Blackwell, pp.433-471.

18 Rusenov A., Nikolov Y., Simeonov R., Chaprazov T., Todorova I. \& Borissov I. 2009. A Case of Fibrous Osteodystrophy in a Dog with Secondary Renal Hyperparathyroidism. Bulgarian Journal of Veterinary Medicine. 12(3): 212-218

19 Silver J. \& Naveh-Many T. 2013. FGF-23 and secondary hyperparathyroidism in chronic kidney disease. Nature Reviews Nephrology. 9: 641-649

20 Thrall M.A., Weiser G., Allison R.W. \& Campbell T.W. 2015. Hematologia e Bioquímica Clínica Veterinária. 2.ed. Rio de Janeiro: Guanabara Koogan, 1590p.

21 Yamamoto S. \& Fukagawa M. 2017. Uremic Toxicity and Bone in CKD. Journal of Nephrology. 30(5): 623-627. 